\title{
The experiment research on flocs based on the micro eddy flocculation
}

\section{technology}

\author{
Dai Hongling ${ }^{1,2, a}$, Qiu Zumin ${ }^{1, b,{ }^{*}}$, Hu Fengping ${ }^{2, c}$, Li Huanhuan ${ }^{2, d}$ \\ ${ }^{1}$ Nanchang University, College of Environmental Science and Engineering, Nanchang 330013 \\ ${ }^{2}$ East China Jiaotong University, Institute of Civil Engineering and Construction, Nanchang 330013

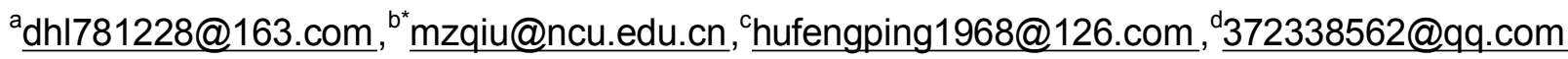

Keywords: flocculation, flocs, equivalent size, numbers

Abstract: The purpose of the paper was to test the floc performance in the process of flocculation by applying to the micro eddy water purification technology and machine vision floc-line detection methods. During the tests, the experiment consisted of detecting the flocs equivalent characteristics such as the size and the quantity, inspecting the influence of the water flow and dosage to the equivalent size and the number of the flocs, exploring the relationship between the particle size and quantity of the flocs and the settled sewage quality.

\section{Introduction}

The conventional water purification process was the most widely used water treatment technology at home and abroad, mainly including coagulation, sedimentation, filtration and disinfection ${ }^{[1-3]}$. The coagulation process was an important part of water treatment and it played a major role in the removal of organic matters ${ }^{[4-6]}$, increasing micro vortex will promote the collision probability of the destabilization particles, therefore, people formed a tiny vortex by setting various mixing equipment, so as to improve the effect of cohesion. The method of forming the micro vortex contained the small mesh grid flocculation pool or micro vortex coagulation new technology and so on $^{[7]}$. In this paper, the new micro-vortex coagulation process ${ }^{[8-9]}$ was adopted, the floc performance was discussed on different flows and dosage.

\section{Materials and methods}

\section{Test reagents and water samples}

During the test, the raw water taken in hole mesh lake of East China Jiaotong University, the raw water quality were shown in Table 1.

Table 1 the raw water quality during the test

\begin{tabular}{cccc}
\multicolumn{3}{c}{ Table 1 } & the raw water quality during the test \\
\hline Serial & number & Water quality index & range \\
\hline 1 & water temperature & $20 \sim 22\left[{ }^{\circ} \mathrm{C}\right]$ \\
2 & $\mathrm{pH}$ & $6.8 \sim 7.2$ \\
3 & $\xi$ electric potential & $-25.69 \sim-24.72[\mathrm{mv}]$ \\
4 & turbidity & $3.984 \sim 6.074[\mathrm{NTU}]$ \\
\hline
\end{tabular}

\section{Test equipment}

The design processing water of the micro eddy flocculation tank was $5 \mathrm{~m}^{3} / \mathrm{h}$, the pond size was $1000 \mathrm{~mm} \times 750 \mathrm{~mm}$ and divided into $12(3 \times 4)$ square cells,.the first nine cells were equipped with 20 HJTM1 type of vortex reactor ${ }^{[10]}$ and the last three each cells with 12 HJTM2 type of vortex 
reactor, Those two vortex reactors' diameter was $\Phi 200 \mathrm{~mm}$, with $25 \mathrm{~mm}$ and $35 \mathrm{~mm}$ surface holes of $50 \%$ and $65 \%$ opening rate. The micro eddy flocculation plan were shown in Figure 1.

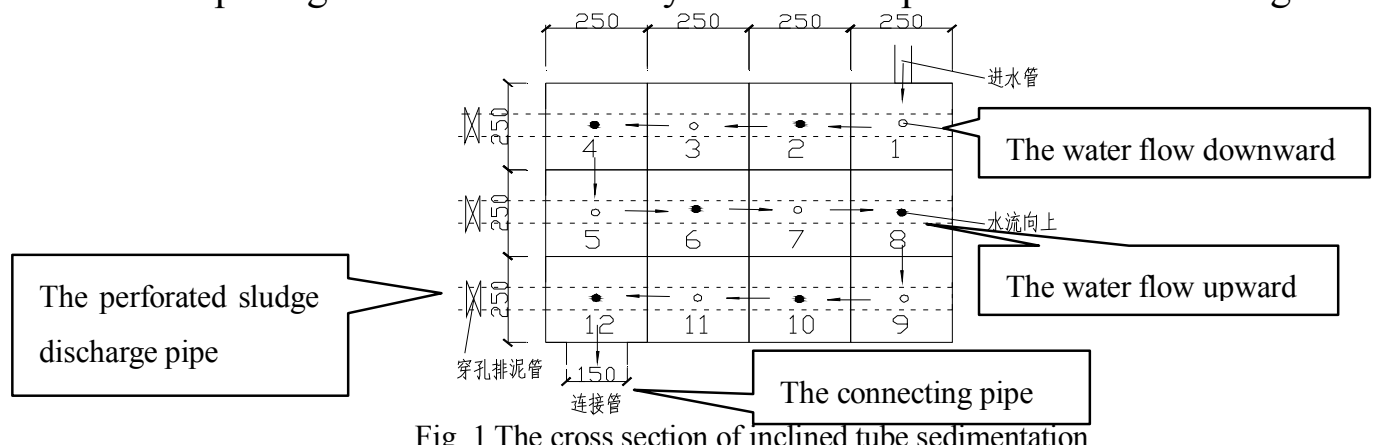

The inclined pipe diameter of the Sedimentation tank was $30 \mathrm{~mm}$, the installation angle is $60{ }^{\circ}$ with $900 \mathrm{~mm}$ length. The length, width and height of the sedimentation tank were $1.75 \mathrm{~m} 、 1.0 \mathrm{~m}$ and $2.3 \mathrm{~m}$. The eddy grid flocculation connected with the inclined tube sedimentation tank via the DN150mm connecting pipe. The cross section of inclined tube sedimentation tank was shown in Figure 2, the micro eddy flocculation and Sedimentation kind was shown in Figure 3.

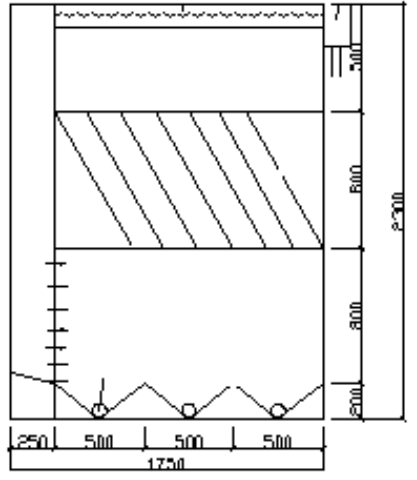

Fig. 2 The cross section of inclined tube sedimentation

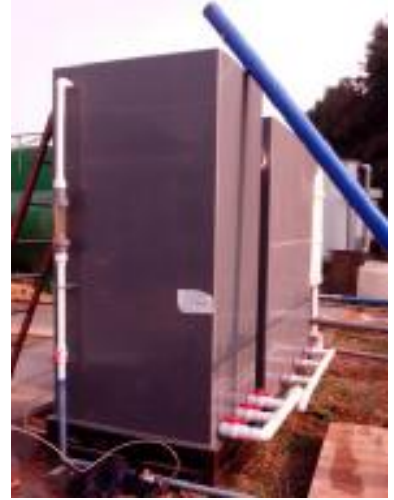

Fig. 3 The micro eddy flocculation and Sedimentation kind

\section{The flocs image processing and parameters determining}

Using the live of machine vision systems ${ }^{[11]}$ to acquisite and handle the floc particles image formed during flocculation process, and the high-quality image acquisition should be with denoising pretreatment ${ }^{[12]}$.After preprocessing, floc recognition processing, morphological analysis, the floc image became clearer and stronger contrast, then scanned and marked the communication unit to the reprocessing floc image ${ }^{[13]}$. The purpose was to get the number v the area and the equivalent particle size or other parameters through the communication field recognition $\operatorname{algorithm~}^{[14]}$.

\section{Results and analysis}

\section{The effect of different influent flows on floc equivalent size and the numbers}

Under the condition of certain PAC coagulant dosage $(18 \mathrm{mg} / \mathrm{L}), \mathrm{CCD}$ camera had taken the floc pictures after the completion of the transition section flocculation at different water flows as shown below figure. $4(\mathrm{a} \sim \mathrm{i})$.

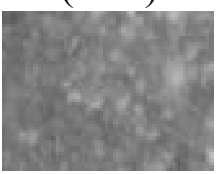

(a) $\mathrm{Q}=2.0 \mathrm{~m}^{3} / \mathrm{h}$

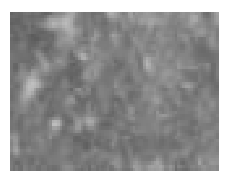

(b) $\mathrm{Q}=2.5 \mathrm{~m}^{3} / \mathrm{h}$

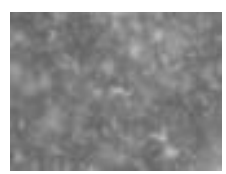

(c) $\mathrm{Q}=3.0 \mathrm{~m}^{3} / \mathrm{h}$ 


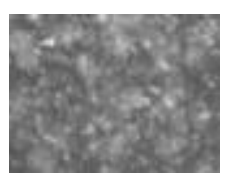

(d) $Q=3.5 \mathrm{~m}^{3} / \mathrm{h}$

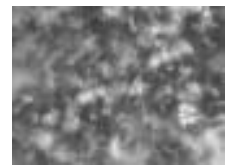

(g) $\mathrm{Q}=5.0 \mathrm{~m}^{3} / \mathrm{h}$

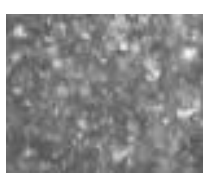

(e) $\mathrm{Q}=4.0 \mathrm{~m}^{3} / \mathrm{h}$

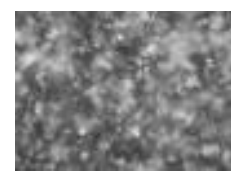

(h) $\mathrm{Q}=5.5 \mathrm{~m}^{3} / \mathrm{h}$
0

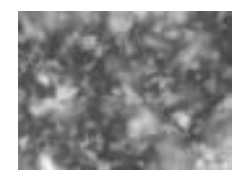

(f) $Q=4.5 \mathrm{~m}^{3} / \mathrm{h}$

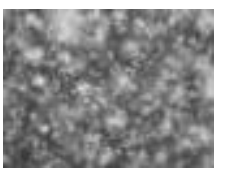

(i) $\mathrm{Q}=6.0 \mathrm{~m}^{3} / \mathrm{h}$

Fig. 4 The flocs images under different water flows

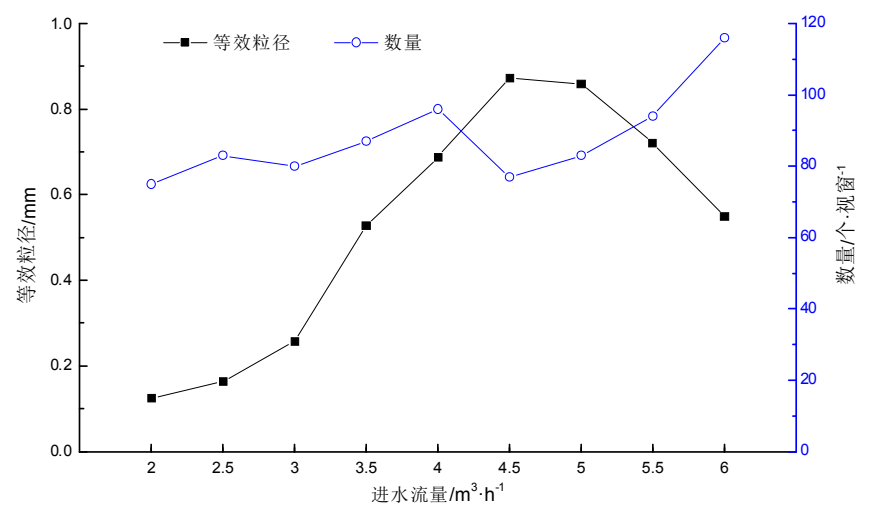

Fig. 5 the Equivalent sizes and the numbers of flocs under different water flows

Figure 5 showed that the floc equivalent diameter generated after flocculation increased gradually from small to large and the numbers were rapidly increasing along with the flows addition; When the water flow changed to $4.5 \mathrm{~m}^{3} / \mathrm{h}$, the flocculation time reduced to $19 \mathrm{~min}$, the hydraulic loading rised to $72 \mathrm{~m}^{3} / \mathrm{m}^{2}$.h, equivalent diameter reached the maximum $0.872 \mathrm{~mm}$, and the numbers were reduced and was 77 every window. Thereafter, with the increase of water flows, the floc equivalent particle size no longer increased, but the number of flocs increased again.

\section{The effect of different dosage $D$ to the floc equivalent size and number}

In certain water flows $\left(\mathrm{Q}=4.5 \mathrm{~m}^{3} / \mathrm{h}\right)$, the floc images photoed at the transition after flocculation with different PAC dosages by CCD camera were listed below figure 6(a i).

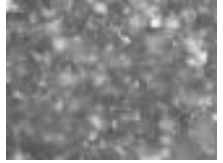

(a) $\mathrm{D}=6.22 \mathrm{mg} / \mathrm{L}$

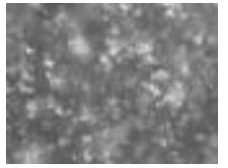

(d) $\mathrm{D}=11.85 \mathrm{mg} / \mathrm{L}$

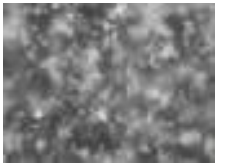

(g) $\mathrm{D}=17.64 \mathrm{mg} / \mathrm{L}$

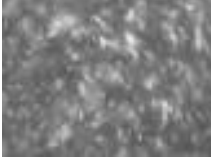

(b) $\mathrm{D}=7.42 \mathrm{mg} / \mathrm{L}$

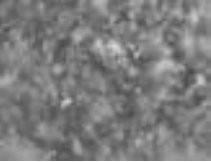

(e) $\mathrm{D}=14.05 \mathrm{mg} / \mathrm{L}$

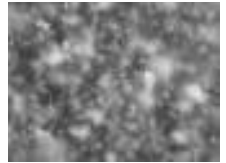

(h) $\mathrm{D}=19.22 \mathrm{mg} / \mathrm{L}$

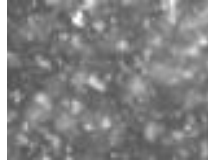

(c) $\mathrm{D}=9.17 \mathrm{mg} / \mathrm{L}$

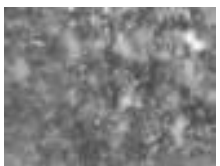

(f) $\mathrm{D}=16.02 \mathrm{mg} / \mathrm{L}$

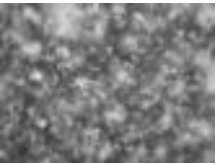

(i) $\mathrm{D}=21.81 \mathrm{mg} / \mathrm{L}$

Fig. 6 The Floc images under different PAC dosages 


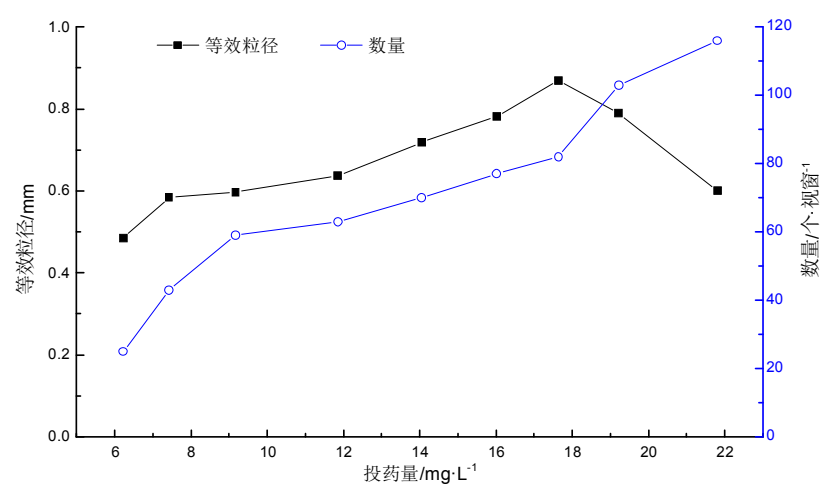

Fig. 7 The effects between different dosages and the floc equivalent diagram and numbers

As seen in Figure 7,As the dosages increased, the floc equivalent particle size will likely grow with also the number; When the dosage was increased to $17.64 \mathrm{mg} / \mathrm{L}$, the resulting flocs equivalent diameter reached to the maximum $0.869 \mathrm{~mm}$, the flocs numbers were 82 every window with a small amplitude; Continue to add the dosage, the resulting flocs equivalent particle size decreased, the numbers went up rapidly conversely.

The effect caused by different dosages to the relationship between the effluent water quality and the floc equivalent size and quantities

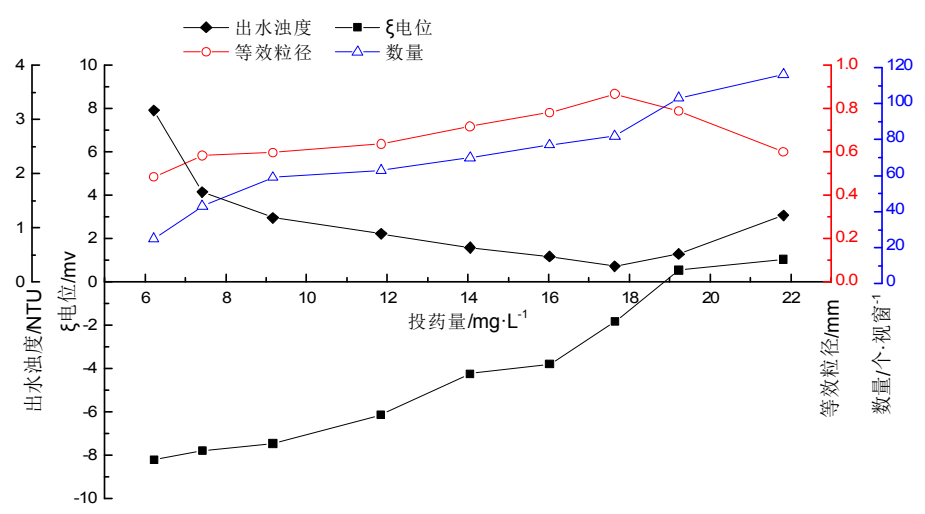

Fig. 8 The relationship between the effluent turbidity and the flocs equivalent diameters and amounts on the case of different dosages

The figure 8 showed that after flocculation, sedimentation with adding PAC coagulants, the effluent turbidity rebounded when reduced to the lowest with the increase of the dosages, when the dosages continued to increase, the trend of the water turbidity and the flocculation floc equivalent particle size was contratry.

\section{Conclusion}

1) As the water flow increase, the flocs equivalent particle size first added, then reduced, the floc numbers decreases a bit after significantly increased and then increase with large amplitude.

2) Equivalent diameter of flocs was gradually increasing with the increase of dosage first then decreases, the floc number increased sharply first, and then after the magnitude smaller bigger.

3 ) The floc equivalent diameter generated after flocculation reaction and the water turbidity was negatively correlated, with water potential was positively correlated. Adding an appropriate amount of coagulant (PAC dosage of this test was $17.64 \mathrm{mg} / \mathrm{L}$ ), water and colloidal flocculated up quickly, the formed floc equivalent particle size was large and not easily broken, the numbers grew slowly and water turbidity was low, the water $\xi$ potential tended to zero but still negative . 


\section{Reference:}

[1] TONG ChaoYang. Introduction to routine treatment of water supply technology in China [J]. Journal of information science and technology of China, 6 (2005) 126-128.

[2] A. F. Saraiva Soares, M. M. D. Leão, M. R. Vianna Neto, E. P. da Costa, M. C. de Oliveira, N. B. Amaral. Efficiency of conventional drinking water treatment process in the removal of endosulfan, ethylenethiourea, and 1,2,4-triazole[J]. Journal of Water Supply: Research and Technology-AQUA, 62 (2013) 367-376.

[3] Tiefu Xu, Chongwei Cui, Cong Ma. Color composition in a water reservoir and DBPs formation following coagulation and chlorination during its conventional water treatment in northeast of China[J]. Desalination and Water Treatment, 54 (2015) 1375-1384.

[4] YUAN Zhibin, WANG Zhansheng. The development and comparison of waterworks water purification process [J]. Water purification technology, 21 (2002) 5-7.

[5] YOU XiaoGong, Chen XiaoQiong. The Coagulation technology and its development [J]. the Industrial water treatment, 22 (2002) 7-9.

[6] Morteza Abbaszadegan, Patricia Monteiro, Nena Nwachuku, Absar Alum, Hodon Ryu. Removal of adenovirus, calicivirus, and bacteriophages by conventional drinking water treatment[J]. Journal of Environmental Science and Health, 43 (2008) 171-177.

[7] Lu PuPing. The experimental study and application of micro vortex flocculation technology [D]. Nanchang: Nanchang university, (2011).

[8] Tong ZhenGong, Hu FengPing. The development and application on the integration of vortices grid clarification process [J]. China water supply and drainage, 26 (2010) 63-68.

[9]Tong ZhenGong,Hu FengPing Fang Yongzhong. Eddy current flocculation clarifying technology used in a water treatment works in Jiaxing [J]. Water supply and drainage, 35 (2009) 15 -17.

[10] LIU YuZhe. The experimental study on the treatment of domestic sewage adopting the eddy current strengthening coagulation clarification technology [D]. Nanchang: The East China Jiaotong University, (2011).

[11] Wei JiLin,Wang YouHong. The application of CCD digital image processing method in the liquid phase flow research [J]. Journal of Taiyuan heavy machinery institute, 23 (2002) 297-300.

[12] LV FengJun. The programe introduction of digital image processing [M]. Tsinghua university press, (1999).

[13] SONG XiaoFeng. The water floc online detection system research [D] : Shanghai: Shanghai university. (2006).

[14] YANG JingZhi. Flow simulation and parameter optimization of vortex coagulation clarifier reaction zone bsaed on FLUENT [D]: NanChang, (2013).

Author introduction: Dai Hongling (1980 -), female, The PoYang of Jiangxi province ,a lecture, a doctoral candidate, the laboratory chief, engaging in the laboratory management, water treatment technology research and teaching. The water supply and drainage teaching and research section of East China Jiaotong University in Nanchang of Jiangxi province, 330013, 13576274317, dh1781228@tom.com.

Fund items: Project supported by the National Natural Science Foundation of China 
International Forum on Energy, Environment Science and Materials (IFEESM 2015)

(61272197);Project supported by the National Natural Science Foundation of China (51268012); Project supported by the Natural Science Foundation of Jiangxi Province (61272197). 